\title{
Heavy Vehicle Propulsion Materials Program: Progress and Highlights
}

D. Ray Johnson Oak Ridge National Lab.

Sidney Diamond U.S. Dept. of Energy 
The appearance of this ISSN code at the bottom of this page indicates SAE'S consent that copies of the paper may be made for personal or internal use of specific clients. This consent is given on the condition, however, that the copier pay a $\$ 7.00$ per article copy fee through the Copyright Clearance Center, Inc. Operations Center, 222 Rosewood Drive, Danvers, MA 01923 for copying beyond that permitted by Sections 107 or 108 of the U.S. Copyright Law. This consent does not extend to other kinds of copying such as copying for general distribution, for advertising or promotional purposes, for creating new collective works, or for resale.

SAE routinely stocks printed papers for a period of three years following date of publication. Direct your orders to SAE Customer Sales and Satisfaction Department.

Quantity reprint rates can be obtained from the Customer Sales and Satisfaction Department.

To request permission to reprint a technical paper or permission to use copyrighted SAE publications in other works, contact the SAE Publications Group.

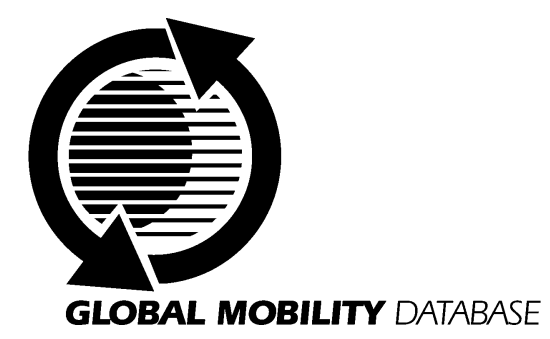

All SAE papers, standards, and selected books are abstracted and indexed in the Global Mobility Database

No part of this publication may be reproduced in any form, in an electronic retrieval system or otherwise, without the prior written permission of the publisher.

ISSN 0148-7191

Copyright 2000 Society of Automotive Engineers, Inc.

Positions and opinions advanced in this paper are those of the author(s) and not necessarily those of SAE. The author is solely responsible for the content of the paper. A process is available by which discussions will be printed with the paper if it is published in SAE Transactions. For permission to publish this paper in full or in part, contact the SAE Publications Group.

Persons wishing to submit papers to be considered for presentation or publication through SAE should send the manuscript or a 300 word abstract of a proposed manuscript to: Secretary, Engineering Meetings Board, SAE.

\section{Printed in USA}




\title{
Heavy Vehicle Propulsion Materials Program: Progress and Highlights
}

\author{
D. Ray Johnson \\ Oak Ridge National Lab. \\ Sidney Diamond \\ U.S. Dept. of Energy
}

Copyright @ 2000 Society of Automotive Engineers, Inc.

\begin{abstract}
The Heavy Vehicle Propulsion Materials Program was begun in 1997 to support the enabling materials needs of the DOE Office of Heavy Vehicle Technologies (OHVT). The technical agenda for the program grew out of the technology roadmap for the OHVT and includes efforts in materials for: fuel systems, exhaust aftertreatment, valve train, air handling, structural components, electrochemical propulsion, natural gas storage, and thermal management. A five-year program plan was written in early 2000 , following a stakeholders workshop. The technical issues and planned and ongoing projects are discussed. Brief summaries of several technical highlights are given.
\end{abstract}

\section{INTRODUCTION}

The history of the Department of Energy's Office of Heavy Vehicle Technologies (OHVT), along with the overall goals and approach of the office, is discussed elsewhere. ${ }^{1-3}$ The primary goals of the Office are as follows:

1. Develop by 2002 the diesel engine enabling technologies to support large-scale industry dieselization of light trucks, achieving a 35\% fuel efficiency improvement over equivalent gasoline-fueled trucks,

2. Develop by 2004 the enabling technology for a class 7-8 truck with a fuel efficiency of $10 \mathrm{mpg}$ (at $65 \mathrm{mph}$ ) which will meet prevailing emission standards, using either diesel or a liquid alternative fuel,

3. Develop by 2004 diesel engines with fuel flexibility and a thermal efficiency of $50 \%$ with liquid alternative fuels, and a thermal efficiency of $50 \%$ with dedicated gaseous fuel.

An assessment of technical barriers to the goals of OHVT identified a number of materials issues. ${ }^{2}$ Materials $R \& D$ needs were further addressed in a workshop held in Knoxville, Tennessee, in August 1999. A web site $^{4}$ was created that includes the 5 -year program plan, technical highlights of the program, and future $R \& D$ plans. Materials $R \& D$ needs identified at the program planning workshop included the following:

\section{PROGRAM GOALS}

Goal 1 - Develop enabling materials to maintain or improve fuel efficiency of class 7-8 truck engines while meeting EPA/Justice Department "Consent Decree" ${ }^{5 "}$ for emissions reduction. September 2002.

Goal 2 - Develop enabling materials for light-duty (class 1-2) diesel truck engines with efficiency over $40 \%$, over a wide range of loads and speeds, while meeting EPA Tier $2^{6}$ emission regulations. September 2004.

Goal 3 - Develop materials solutions to enable heavyduty diesel engine efficiency of $50 \%$ while meeting the emission reduction goals identified in the EPA-proposed rule for heavy-duty highway engines ${ }^{7}$. September 2006.

\section{MATERIALS R\&D REQUIREMENTS}

Various types of advanced materials are needed to meet the goals of the diesel engine industry and DOE. The materials chosen for development in the program are chosen by means of technology pull: that is, by the requirements of diesel engine industry to meet the technical and programmatic goals of OHVT. Relevant materials include the following: high-temperature alloys, intermetallic alloys, cermets, ceramics, bulk amorphous metals, ceramic and metal-matrix composites, and thermal barrier and wear coatings

The materials requirements are organized by major engine subsystem and are summarized below.

FUEL SYSTEMS - The fuel systems for diesel engines are complex, expensive systems that are critically important to meeting the efficiency and emissions targets of 
OHVT. Virtually every path to improving control of the combustion process in order to improve efficiency and lower emissions depends on improvements in the fuel injection system. Presently, the fuel system and air-handling system represent a significant portion of the cost of a heavy-duty diesel engine.

Enabling materials and cost-effective, precision manufacturing processes are instrumental in developing improved fuel injection systems.

The electronic fuel injectors on heavy-duty diesel engines operate at high pressure, about 20,000 psi, in order to minimize particulate emissions. The fuel injection pressure is likely to increase, to as much as $35,000 \mathrm{psi}$, to meet emerging emissions regulations. The high-pressure fuel injection results in problems with wear and scuffing of fuel injector plungers and erosion, wear, and fatigue of fuel injector nozzles. In addition, low-sulfur fuels typically do not lubricate the fuel injector components as well as current diesel fuel; the ultra-low sulfur fuels expected in the near future may exacerbate the need for wear and scuff resistant materials.

Fuel injectors are highly precise systems. The individual components must fit together with clearances sometimes smaller than $1 \times 10^{-6}$ meters. Control of the combustion process requires precise control of the size, shape, and surface finish of the injector components. In addition to new and improved materials, improved manufacturing and inspection methods for the injector components are needed as well.

Although a single fuel injection event occurs in a brief fraction of a second, greater control of the rate and timing of the injection event is necessary to improve the control of combustion and resulting efficiency and emissions. Pilot injection, for example, has been shown to reduce NOx by spreading out the combustion event over time and, thus, reduce the maximum combustion temperature. Further reductions in NOx might be realized by spreading out the injection into several events, all of which must occur within a very brief time. The current systems for reliably controlling multiple injections are limited by the ability of mechanical and electronic systems to respond precisely and quickly enough to provide the additional control of injection. Smart materials, such as piezoelectric materials and magnetostrictive materials, offer the potential of better control of fuel injection, but a number of improvements in the materials and manufacturing methods for the materials are yet required.

EXHAUST AFTERTREATMENT - The reduction of NOx and particulate emissions is critically important to OHVT's program and is highly materials dependent. Significant reductions in exhaust emissions will require improvements in engine design, advanced and integrated exhaust control technologies, and improved fuel quality. Advanced engine control technology may require quantitative, real-time NOx sensors, miniature ceramic electrochemical cells, as on-board diagnostic and control devices.

Sulfur in diesel fuel is a major barrier to several promising aftertreatment technologies. Current U.S. diesel fuel contains up to $500 \mathrm{ppm}$ sulfur. The diesel engine community believes the fuel sulfur must be reduced to 30 ppm or less to achieve expected environmental regulations for the year 2007. The Environmental Protection Agency is currently involved in rule making that will likely lead to low $(30-50 \mathrm{ppm})$ sulfur fuel becoming widely available in the 2004 timeframe. For the purposes of our program plan, it is assumed that the 2004 goals must be met with current 500-ppm-sulfur diesel fuel. Even when 50or 30-ppm-sulfur fuel becomes available, catalyst poisoning will continue to be an issue for durability of exhaust aftertreatment devices. Development of sulfur-tolerant catalysts and sulfur-removal technologies (SOx absorbers) is considered critically important to this program.

Catalysts are typically high-surface-area materials. The behavior of catalysts is strongly influenced by microstructure, which is in turn determined by processing history and exposure conditions. The characterization of catalyst systems shares methodology common to many materials systems, e.g., high-resolution microscopy and microanalysis using primarily electrons and photons. The synthesis and processing of catalyst systems (substrate, washcoat, catalyst particles) are also familiar to the materials research community. R\&D projects are expected to include synthesis and processing studies, bench test and engine exposures, and postmortem analysis of the chemistry and microstructure of the catalyst systems.

Durability of exhaust aftertreatment systems in heavy vehicles is a concern. Lifetimes of at least 500,000 miles are expected, and 1,000,000 miles is desired (compared to 100,000 miles for automobiles). Exposure of the aftertreatment systems to high temperature, vibration, erosion, and chemical attack by species in the oil and fuel will result in degradation of performance. Characterization of the effects of exposure in service on the microstructure and microchemistry of the aftertreatment systems will be needed and may lead to development of more durable systems.

In addition to the emissions regulated by the EPA, unregulated emissions, such as $\mathrm{N}_{2} \mathrm{O}, \mathrm{H}_{2} \mathrm{~S}, \mathrm{COS}, \mathrm{NH}_{3}$, polyaromatic hydrocarbons (PAHs), etc., are becoming increasingly important. The effect of exhaust aftertreatment systems on unregulated emissions will have to be determined and quantified and steps taken to minimize the unregulated emissions. 
The following is a very brief listing of exhaust aftertreatment technologies that may be relevant: ${ }^{8}$

Lean NOx Catalysts - Reduction of NOx in a highly oxidizing atmosphere is difficult. The introduction of a reductant, diesel fuel or other hydrocarbon, into the exhaust is required, and may introduce a fuel economy penalty of $3 \%$ or more. The catalyst typically employs a zeolite wash coat, which is thought to provide a reducing microenvironment. Combinations of catalysts, e.g., noble metals $(\mathrm{Pt})$, base metals $(\mathrm{Cu})$, may be used to broaden the operating temperature window. Currently, peak NOx conversion efficiencies are around $30 \%$, which are unacceptably low. R\&D to develop robust, cost-effective lean NOx catalyst systems with higher conversion efficiencies is needed.

NOx Absorbers - Precious metal catalysts oxidize NO to $\mathrm{NO}_{2}$. The $\mathrm{NO}_{2}$ is then stored in an alkaline earth oxide, e.g., $\mathrm{BaCO}_{3}$, as a nitrate. In the reduction step, a small injection of diesel fuel releases the stored NOx and, in the presence of rhodium or another precious metal, the $\mathrm{NOx}$ is converted to $\mathrm{N}_{2}$. A fuel economy penalty of $3 \%$ or more will result from the injection of diesel fuel into the exhaust. $\mathrm{SO}_{2}$ can be catalytically converted to sulfate, resulting in higher particulate matter (PM) emissions. Very high conversion efficiencies, $50-90 \%$, have been demonstrated. However, the precious metal catalysts and alkaline earth oxide storage media are poisoned by sulfur.

Selective Catalytic Reduction (SCR) - Ammonia is used as a reductant, with either aqueous ammonia or aqueous urea carried onboard. The reduction is carried out in the presence of catalysts. Multiple catalysts may be used to broaden the temperature window. The catalysts for the low temperature end of the range are sulfur sensitive. SCR, which can achieve NOx reductions in excess of $90 \%$, is the only proven technology capable of meeting the program goals for NOx reduction. However, SCR would require the trucker to carry and handle an additional material, urea or ammonia, for which the infrastructure does not exist. SCR also raises other concerns including release of ammonia in the exhaust stream, and SCR technology has not been proved in mobile applications.

Plasma Assisted Catalyst - A new, unproven technology involves using a plasma to generate high-energy electrons. $\mathrm{NO}$ is oxidized to $\mathrm{NO}_{2}$ in the plasma, followed by catalytic reduction using a hydrocarbon reductant $\left(\mathrm{NO}_{2}\right.$ is more easily reduced under these conditions than NO.) Laboratory NOx reductions of $80 \%$ have been achieved. The plasma power requirements and fuel economy penalty from injecting diesel fuel (or other hydrocarbon) as a reductant are concerns. $R \& D$ needs include testing under realistic conditions, materials and manufacturing methods for the dielectric materials, and catalyst efficiency and durability.
Oxidation Catalysts - These catalysts, usually noble metals, oxidize carbon monoxide and gaseous and liquid hydrocarbons, including the soluble organic fraction that makes up part of the particulate emissions. Control of the SOF can result in reduction of the particulate matter emissions by 25 to $50 \%$. Oxidation catalysts are a proven technology, applied to new engines and retrofits, and shown to be very durable. However, fuel sulfur can be oxidized to sulfate and emitted as sulfuric acid, contributing to the PM and, in some cases, increasing the $\mathrm{PM}$ to higher levels than the engine out emission. More effective oxidation catalysts can be developed if fuel sulfur is reduced to low levels.

Particulate Matter Filters - This technology consists of a filter material (porous monolith or fibrous material) that collects the solid and liquid particulate emissions. The collected PM is disposed of by oxidizing the particulate and thus regenerating the filter. The regeneration temperature can be reduced to a value consistent with diesel exhaust by catalysis. Alternatively, the PM can be oxidized by an auxiliary source of heat. The catalyst can be applied directly on the filter material, incorporated into the fuel, or applied upstream of the filter. Particulate emissions reductions of up to $90 \%$ have been achieved in Europe on trucks and buses. Efficiency losses due to backpressure and energy required for regeneration are concerns. R\&D issues include cost and durability of the filters.

VALVE TRAIN - Materials are an enabling technology for durable valve train components in advanced engines. Fuel sulfur and other contaminants are corrosive for diesel engine valves. Exhaust gas recirculation (EGR) required to meet Goal 1, will increase the average temperature, pressure, and corrosive species in contact with the valve face and seat and, thus, accelerate valve failure. Valve stem-valve guide seals will have to be completely leakproof to meet the particulate material requirements of Goal 3. Lower reciprocating mass in valve train components will reduce stress in higher RPM light-duty engines. Research and development is needed to develop lightweight, wear- and corrosion-resistant valve train materials (valves, valve seats, valve guides, rollers, rocker arms) for use in all classes of heavy-duty diesel engines.

New concepts for joining of dissimilar materials (e.g., intermetallic valve head to steel shaft) are needed to reduce the cost of new valve materials.

AIR HANDLING - Turbocharging and associated air handling equipment are important elements of engine control for heavy-duty diesel engines. Advanced engines will place new demands on the air handling system. Exhaust gas recirculation (EGR) will likely be required to meet the year 2002 emission requirements. EGR introduces problems with corrosion of heat exchanger components for cooling the EGR, and makes it necessary to increase the 
turbocharger boost in order to maintain the necessary oxygen partial pressure in the combustion chamber. Corrosion-resistant materials for EGR coolers will be needed. Also, the additional heat of compression will push conventional aluminum compressor materials to temperatures at which creep deformation will be a problem; higher-temperature compressor alloys will be necessary.

EGR will need valving and controls. Therefore, corrosion-resistant materials for EGR valves will be needed.

Advanced engine control strategies require continuous control of the inlet air pressure, making variable-geometry turbochargers and continuously variable wastegate valves necessary. The linkage to control the variablegeometry turbocharger inlet and wastegate valve operates at high temperature (up to $600^{\circ} \mathrm{C}$ ) and without liquid lubrication. Better materials are needed for the linkage.

In addition, the inertia of the turbocharger limits the ability of the system to respond as rapidly as desired. Lowermass materials for turbocharger rotors are needed.

Air handling represents a significant fraction of the cost of a heavy-duty diesel engine. The performance requirements referenced above must be met with cost-effective materials and manufacturing methods.

STRUCTURAL AND INSULATING MATERIALS - Meeting Goal 3, 50\% efficiency in an engine which meets the emission reduction goals identified in the EPA proposed rule for heavy-duty highway engines, will likely involve higher specific power. Higher specific power will call for higher peak cylinder pressure and brake mean effective pressure (BMEP). The higher pressures require costeffective materials with higher strength and fatigue resistance for engine blocks and cylinder heads. Either higher-quality cast iron will be needed, or, alternatively, highly stressed areas in conventional cast iron components can be reinforced with high-strength materials.

For light-duty engines in particular, there is a need to reduce the weight of the engines to make them competitive with spark ignition engines. Research and development is needed for aluminum alloy engine blocks and cylinder heads with the strength and fatigue resistance necessary for the high-efficiency direct-injection diesel engine.

Exhaust gas recirculation, EGR, which is necessary for meeting Goal 1, will increase the overall temperature of the engine hot section and exhaust path. The exhaust manifold and turbocharger housing will be subjected to high thermal loads and oxidation and corrosion conditions. Research is needed to develop cost-effective alloys for exhaust manifolds and turbocharger housings.

Selected insulation of hot section and exhaust components to reduce heat rejection has been used to increase diesel engine efficiency in OHVT's LE-55 research program. While engine efficiencies up to $55 \%$ were demonstrated in a single-cylinder engine, the insulating materials used in the demonstration are not available as durable, cost-effective components. Research is needed for durable thick thermal barrier (TTBC) coatings, monolithic or coated cylinder head plates with low thermal conductivity, and insulated exhaust ports.

STANDARDS - The commercialization of new materials technologies is dependent on having standard testing methods which are accepted by the industry. Materials testing standards in the U.S. are primarily voluntary consensus standards by the American Society for Testing and Materials (ASTM). The ASTM standards are coordinated with international standards activities by the International Standards Organization (ISO). Discussions are being held with domestic and foreign diesel engine manufacturers and suppliers to determine the interest in collaboration in pre-competitive round-robin testing of relevant diesel engine materials. If sufficient interest exists, a program involving participation of U.S. and foreign companies under the umbrella of the International Energy Agency will be initiated.

ELECTROCHEMICAL PROPULSION MATERIALS OHVT will initiate a new Heavy Hybrid truck program in FY 2000. The Heavy Hybrid Vehicle program will be a cooperative industry-government program for the development of advanced hybrid electric powertrain technology utilizing reciprocating natural gas engines for urban cycle trucks and buses. The objective is to support and accelerate the commercial introduction of hybrid vehicle technology in the truck and bus market. While the initial effort will focus on natural gas heat engines, the longerterm focus for hybrid vehicles will be fuel cells. Solid oxide fuel cells (SOFCs) have many advantages for clean, efficient hybrid vehicles.

The following challenges and barriers must be overcome for SOFCs to be utilized for transportation power applications. The main barriers for use of SOFCs relates to integration of improved design, materials, and fabrication processes to increase performance and lower fabrication and manufacturing costs. Alternate configurations for SOFC, such as advanced planar designs, are required to achieve high power generations and lower fabrication costs. The materials issues that must be addressed include the development of: 1) low-temperature mixed conducting electrodes, 2) metallic interconnects with a conductive coating, and 3) seal technology.

SOFC technology requires the emphasis to be changed from large SOFC power generation to small generators that can be scaled to larger size. Reduction in cold-startup times and the ability of the device to thermal cycle may also be barriers. Fuel processing and reforming of the more complex liquid fuel and stability in fuel impurities must be addressed. Research and development must be directed to solving the above issues specifically as they related to lower fabrication costs and high performance. 
GAS STORAGE MATERIALS - On-board storage of natural gas in heavy vehicles could potentially enable huge savings in petroleum imports. However, the technology for storage of CNG on-board has been problematic in several regards; high cost, safety concerns, and limited range. A recent discovery, monolithic, microporous carbon fiber composite material for storage of natural gas by relatively low-pressure adsorption, may enable extensive use of natural gas in transportation. ${ }^{9}$

The objective of the gas storage project (part of the OHVT Systems Technology Program) is to develop a monolithic, adsorbent, carbon material capable of storing greater than $180 \mathrm{~V} / \mathrm{V}$ of natural gas at $3.5 \mathrm{MPa}$ and ambient temperature. Retentivity, the tendency of activated carbon to retain adsorbed gases, will be minimized using a novel electrical desorption technique. Previous efforts have been successful in developing a monolithic material, based on carbon fibers, capable of storing $>150 \mathrm{~V} / \mathrm{V}$ of methane at $3.5 \mathrm{MPa}(500 \mathrm{psi})$ and ambient temperature. The monoliths are slurry molded and hot pressed from green forms made from isotropic fibers and phenolic resin. The monoliths are activated in $\mathrm{CO}_{2}$ to attain the optimum combination of bulk density and micropore volume.

Propulsion Materials will provide support to this effort by means of materials characterization, in particular with the aberration-corrected transmission electron microscope (ACEM) to be located in the High Temperature Materials Laboratory. The ACEM is expected to enable resolution of 0.7 Angstrom, which will allow us to see individual atoms. High-resolution transmission electron microscopy will be used to verify predictions of computer models of the location of gas atoms on the carbon storage media surface. These results will then be used as feedback in the computer modeling effort and as a guide in optimizing the processing of the carbon storage media.

THERMAL MANAGEMENT MATERIALS - Thermal management is very materials intensive. Development, characterization, and testing of advanced materials will be important for thermal management in engines. For example, a relatively simple technique for fabricating extremely high thermal conductivity carbon foams has recently been developed at the Oak Ridge National Laboratory. The technique produces a mesophase pitchbased graphitic foam with extremely high thermal conductivity and an open celled structure. The cell walls are made of oriented graphitic-like planes, similar to high-performance carbon fibers. In fact, it is estimated that the thermal conductivity of the cell walls is greater $1500 \mathrm{~W} /$ $\mathrm{m} \cdot \mathrm{K}$ (copper is $400 \mathrm{~W} / \mathrm{m} \cdot \mathrm{K}$ ). Moreover, due to the low density, the specific conductivity of the foam is over 5 times that of copper and over 4 times that of aluminum. The open porosity yields a relatively large specific surface area $\left(>20 \mathrm{~m}^{2} / \mathrm{g}\right)$, improving heat transfer to a working fluid. In fact, by utilizing the graphite foam, heat transfer coefficients up to two orders of magnitude greater than current heat exchangers have been measured. This will lead to extremely efficient and lightweight heat exchangers such as radiators and EGR coolers. Other thermal management devices, such as heat pipes, may enable higher performance engines. Thermal management in SOFCs (see the Electrochemical Materials section above) is likely to be a critical issue, both in terms of controlling the operating temperature and minimizing heat loss when the cell is not operating. Cost effective advanced materials will be needed for thermal management of solid oxide fuel cells.

\section{TECHNICAL HIGHLIGHTS}

Selected technical highlights are listed below:

CHARACTERIZATION OF DIESEL AND SI EXHAUST PARTICULATE - A protocol has been developed ${ }^{10}$ by ORNL for collecting transmission electron microscopy (TEM) specimens of exhaust particulate matter during dynamometer tests. The TEM used in the study is capable of resolution of compositional information within a 1$\mathrm{nm}$ spot size. The diesel particulate matter was observed to consist of chains of small spheres of turbostratic carbon; the particles observed consisted almost entirely of carbon and oxygen. In the case of an SI engine with extreme engine wear, particulate matter that was amorphous in structure and contained significant quantities of zinc and lead was observed.

LIFE PREDICTION AND MECHANICAL RELIABILITY OF A CERAMIC VALVE MATERIAL - Mark Andrews of New Mexico State University completed a Ph.D. dissertation on Life Prediction and Mechanical Reliability of NT551 Silicon Nitride. ${ }^{11}$ The inert strength and fatigue performance of a diesel engine exhaust valve made from silicon nitride ceramic were assessed. The silicon nitride characterized was manufactured by Saint Gobain/Norton Industrial Ceramics and was designated NT551. The evaluation was made by utilizing a probabilistic life prediction algorithm that combined censored test specimen strength data with a Weibull distribution function and the stress field of the ceramic valve obtained from finite element analysis. The major assumptions of the life- prediction algorithm are that the bulk ceramic material is isotropic and homogenous and that the strength-limiting flaws are uniformly distributed.

Fractographic analysis identified four different failure modes; two were identified as inhomogenities that were located throughout the bulk of NT551 and were due to processing operations. The fractographic analysis concluded that the strength degradation on NT551 observed from the temperature and loading rate test parameters was due to a change of state that occurred in the secondary phase.

Predicted and actual fatigue performance did not correlate well; the predictions were conservative. The results 
emphasize the requirement that materials be homogenous and strength-limiting flaws be uniformly distributed as a prerequisite for accurate life prediction and reliability analyses.

HIGH SPEED AND HIGH MATERIAL REMOVAL RATE GRINDING OF CERAMIC ENGINE COMPONENTS Researchers at North Carolina State University, Cummins Engine Company, and ORNL investigated "High Speed and High Material Removal Rate Grinding of Ceramics Using the Vitreous Bond CBN Wheel. ${ }^{12}$ "

Grinding experiments were conducted in three phases: 1) the effects of wheel speed and dressing speed ratio on grinding forces, specific grinding energy, part roundness, and part surface finish were investigated, 2) the effects of material removal rate (in-feed) and dwell time on specific grinding energy, part roundness, and surface finish were investigated, and 3) the effects of wheel speed and part material on wheel wear were investigated. The grinding experiments were carried out on a Weldon Model AGN5 Cylindrical grinder. The authors concluded that highspeed grinding of ceramic materials has numerous advantages: higher material- removal rates, higher grinding ratio, lower grinding forces, smaller effective chip thickness, better surface finish, improved form control, and lower cost of operation.

REMOTE TRANSMISSION ELECTRON MICROSCOPY TECHNIQUES IN DIESEL NOX CATALYST RESEARCH L. F. Allard of ORNL and C. K. Narula of Ford Research Laboratory have investigated TeleMicroscopy techniques in catalyst research for NOx reduction in diesel engines. ${ }^{13-14}$ The experiments were conducted remotely on the HF-2000 transmission electron microscope at ORNL from Ford Motor Company's Scientific Research laboratory in Dearborn, Michigan.

Pt clusters on titania particles are potential NOx reduction catalysts. A sample with poor performance showed large $\mathrm{TiO}_{2}$ particles with a non-uniform dispersion of $\mathrm{Pt}$ clusters. After the first on-line session, a new catalyst was prepared, and within one week was examined during another remote session. A much finer titania particle size with a uniform dispersion of $0.5-\mathrm{nm}$ clusters of Pt produced better catalyst performance. The new $\mathrm{Pt} / \mathrm{TiO}{ }_{2}$ sample was reacted in the HTML's special ex-situ catalyst reactor, under conditions to simulate real catalyst exposures during use. After reaction, the same catalyst area shows sintering of the $\mathrm{TiO}_{2}$ support, and agglomeration of the Pt clusters.

EFFECT OF ALUMINA PROPERTIES ON DIESEL NOX REDUCTION - Researchers at Caterpillar Inc.'s Technical Center investigated "The Effect of Alumina Properties on the Catalytic Performance of NOx Reduction. ${ }^{15}$ " Various alumina powder samples were tested for their ability to catalytically reduce $\mathrm{NOx}$ under lean condition $(0.1 \%$ NOx, $0.1 \%$ propene, $9 \% \mathrm{O}_{2}, 7 \% \mathrm{H}_{2} \mathrm{O}, 0.2 \mathrm{~g}$ sample size,
$200 \mathrm{cc} / \mathrm{min}$ gas flow). The surface area, pore volume, and pore-size distribution of alumina samples were measured with the BET technique. Impurities in the alumina samples were quantified by inductively coupled plasma. These results were correlated with the NOx reduction data (NOx and $\mathrm{NO}_{2}$ reduction) to understand the effect of alumina properties (chemical/physical) on the lean-NOx activity. The pore volume and impurity content had a significant effect on the lean-NOx performance of alumina. The sulfate level in alumina has the most significant influence on the de-NOx performance, with a low impurity content being most desirable. The optimum pore volume was determined to be larger than $1.0 \mathrm{cc} / \mathrm{g}$. However, the de-NOx performance of alumina was not affected significantly by the surface area or average pore size of the material. The catalytic performance of all aluminas was enhanced dramatically when $\mathrm{NO}$ was replaced with $\mathrm{NO}_{2}$ in the gas feed stream.

THE EFFECTS OF THERMAL BARRIER CERAMIC COATINGS ON THE PERFORMANCE OF A DI DIESEL ENGINE - The purpose of this research by L. Russel et al. at North Carolina A\&T State University ${ }^{16}$ was to develop a systematic approach to understanding both the material behavior and the thermodynamic influence of thermal barrier coatings in diesel engines. The piston crown, cylinder head, valve faces, and cylinder liner of a single-cylinder Ricardo Hydra DI diesel engine were treated with thin thermal barrier coatings by Adiabatics, Inc. The piston crown and bowl received a $0.25-\mathrm{mm}$ plasma-sprayed coating of $85 \%$ partially calcium stabilized zirconia, $10 \%$ tungsten cobalt chrome powder, and $5 \%$ chrome oxide. The head and valves were coated with a $0.5 \mathrm{~mm}$ thermal barrier coating incorporating $5 \%$ hollow alumina spheres in a slurry of $65 \%$ silica, $15 \%$ partially-stabilized zirconia (PSZ), 7\% tungsten chrome powder, and $8 \%$ chrome oxide. The liner received a $0.75-\mathrm{mm}$ plasma-sprayed coating of yttria-stabilized zirconia in the region above the top ring travel, plus a 0.2 $\mathrm{mm}$ slurry- sprayed PSZ wear coating over the entire surface.

The effects of various coating schemes on fuel consumption and emissions vary with engine load, speed, and injection timing. For the case of $2500 \mathrm{rpm}$ and 8 DBTDC, the coated piston produced the lowest fuel consumption, while the coated liner produced the highest. The coated piston and coated liner both reduced NO emission under this condition relative to the baseline engine, while the coated head and all-surfaces- coated case increased NO emission.

The coated piston showed numerous visible microcracks after engine testing. Microstructural evaluation showed a high level of porosity. Microhardness profiles showed significant variation in hardness in the coatings. The hardness levels out as the profile approaches the interface with the base aluminum alloy and levels off to a consistent value in the aluminum. 
RAMAN AND FLUORESCENCE SPECTROSCOPIC CHARACTERIZATION OF CERAMIC MATERIALS: STRESS, PHASE, AND TEMPERATURE - Michael Lance of ORNL investigated two relatively novel techniques in the field of materials science, Raman and fluorescence spectroscopy. ${ }^{17}$ These techniques have recently been applied to measuring local stresses and phases in ceramics with a high degree of success. Both techniques utilize the same equipment and have a spatial resolution of approximately 2 micrometers, far exceeding the resolution of standard X-ray techniques. Stress measurement (i.e., piezospectroscopy) relies on the stress-induced shifts of characteristic vibrational or electronic energy levels of ceramics while strained. Measurement time is greatly reduced as compared to neutron diffraction methods that are currently more suited to extracting stress gradients on a macroscopic scale.

The experimental equipment consists of a laser focused through a standard optical microscope onto the sample. The scattered light is then collected back into the microscope and directed into a monochromator where it is dispersed and detected using a CCD (charge coupled device.) The microscope can either be used to probe around the sample or to collect spectra. The Raman microprobe at ORNL is completely automated which allows for the simple measurement of stress or phase distributions. One can also do depth-profiling, depending on the transmittance of the material being examined.

\section{SUMMARY}

The Office of Heavy Vehicle Technologies has ambitious goals for the development of clean, high-efficiency trucks. An assessment of technical barriers to the attainment of OHVT's goals identified a number of requirements for improved materials, materials characterization and testing data and methodology, and manufacturing technology. The Heavy Vehicle Propulsion Materials Program was initiated as a government-industry-university partnership to develop enabling materials technology for heavy vehicle engines. The candidate materials to be investigated in the program are chosen by technology pull from the diesel engine manufacturers and their component suppliers. A comprehensive program is ongoing, including projects in

- materials for fuel systems,

- materials for exhaust aftertreatment,

- materials for valve-train components,

- structural and insulating materials,

- materials standards,

- electrochemical propulsion materials,

- gas storage materials, and

- thermal management materials.
Tentative technical plans have been developed through 2004 and beyond. A technology assessment and program planning activity are continuing, and resulting in a multiyear program plan in the first quarter of the year 2000.

\section{ACKNOWLEDGMENTS}

Research sponsored by the U.S. Department of Energy, Assistant Secretary for Energy Efficiency and Renewable Energy, Office of Transportation Technologies, as part of the Heavy Vehicle Propulsion Materials Program, under contract DE-AC05-00OR22725 with UT-Battelle, LLC.

\section{REFERENCES}

1. Multiyear Program Plan for 1998-2002, DOE/ORO2071, U.S. DOE, Office of Heavy Vehicle Technologies (OHVT), Office of Transportation Technologies, August 1998.

2. OHVT Technology Roadmap, DOE/OSTI-11690/R1, U.S. DOE, Office of Heavy Vehicle Technologies, Office of Transportation Technologies, February 2000.

3. Diamond, Sidney and D. Ray Johnson, "Heavy Vehicle Propulsion Materials Program," SAE 1999-012254, Government/Industry Meeting, Washington, D.C., April 26-28, 1999.

4. http://www.ms.ornl.gov/programs/energyeff/hvpm.

5. http://www.epa.gov/oeca/ore/aed/diesel/index.html.

6. 40 CFR Parts 80 and 86, Environmental Protection Agency.

7. Notice of Proposed Rule Making (NPRM) on the new federal HD standards, expected to be published early in 2000. Also presented at Advancements in Clean Diesel Technology, SAE TOPTEC, September 30, St. Petersburg, Florida.

8. Tutorial information taken from www.meca.com, courtesy of the Manufacturers of Emission Controls Association.

9. Burchell, Tim and Mike Rogers, "Low Pressure Storage of Natural Gas for Vehicular Applications," SAE 2000-01-2205, presented at the SAE Government/ Industry Meeting, Washington, DC, June 19-21, 2000.

10. Nolan, T. A. and D. Blom, ORNL, personal communication.

11. Andrews, M. J. et al., "Strength and Fatigue of NT551 Silicon Nitride and NT551 Diesel Exhaust Valves," ORNL/TM-1999/332, in press, 2000.

12. Shih, A. J. et al., "High Speed and High Material Removal Rate Grinding of Ceramics Using the Vitreous Bond CBN Wheel," presented at the 1998 Annual Meeting of the American Society for Precision Engineering, October 25-30, 1998.

13. Narula, C. K., L. F. Allard, and G. W. Graham, "SolGel Processed Fluorite-Structured PrOy-ZrO $\mathrm{Zr}_{2}$ Mixed Oxides Deposited on Alumina," J. Mater. Chem. 9(5) 1155-1159 (1999). 
14. Narula, C. K., M. Rokosz, L. F. Allard, R. J. Kudla, and M. S. Chattha, "Sol-Gel Processed Silica-Alumina Materials for Diesel Engine Emissions Reduction Catalysts," Langmuir 16, 3818 (2000).

15. Park, Paul W., Kent A. Koshkarian, and Michael J. Readey, "The Effect of Alumina Properties on the Catalytic Performance of NOx Reduction," presented at the Diesel Engine Exhaust Reduction (DEER) Workshop 99, Castine, Maine, July 5-9, 1999.

16. Russel, L., D. Klett, and J. Sankar, "The Effect of Ceramic Thermal Barrier Coatings on the Performance of a DI Diesel Engine," in Proceedings of ICCE/5, Las Vegas, Nevada, July 5, 1998.

17. Lance, M., ORNL, personal communication.

\section{CONTACT}

D. Ray Johnson, Oak Ridge National Laboratory, P.O. Box 2008, Oak Ridge, TN 37831-6066.

Phone: 865/576-6832; Fax: 865/574-6098;

E-mail: johnsondr@ornl.gov 